Published in final edited form as:

Catheter Cardiovasc Interv. 2014 October 1; 84(4): 646-651. doi:10.1002/ccd.25465.

\title{
The efficacy of "hybrid" percutaneous coronary intervention in chronic total occlusions caused by in-stent restenosis: insights from a US multicenter registry
}

\author{
Georgios Christopoulos, MD1, Dimitri Karmpaliotis, MD², Khaldoon Alaswad, MD³, William \\ Lombardi, MD ${ }^{4}$, Aaron Grantham, MD ${ }^{5}$, Bavana V. Rangan, BDS, MPH ${ }^{1}$, Anna P. Kotsia, \\ MD', Nicholas Lembo, MD², David Kandzari, MD², James Lee, MD², Anna Kalynych, MD², \\ Harold Carlson, MD $^{2}$, Santiago Garcia, MD $^{6}$, Subhash Banerjee, MD ${ }^{1}$, Craig A. Thompson, \\ M.D., $\mathrm{MMSc}^{7}$, and Emmanouil S. Brilakis, MD, $\mathrm{PhD}^{1}$ \\ ${ }^{1}$ VA North Texas Healthcare System and UT Southwestern Medical Center, Dallas, TX \\ 2Piedmont Hospital, Atlanta, GA \\ ${ }^{3}$ Appleton Cardiology, Appleton, WI \\ ${ }^{4}$ PeaceHealth Cardiology, Bellingham, WA \\ ${ }^{5}$ Mid America Heart Institute, Kansas City, MO \\ ${ }^{6}$ Minneapolis VA Healthcare System and University of Minnesota, Minneapolis, Minnesota, USA \\ ${ }^{7}$ Yale University School of Medicine, New Haven, CT
}

\begin{abstract}
Objectives-To examine the success and complication rates in percutaneous coronary intervention (PCI) for chronic total occlusion (CTO) caused by in-stent restenosis (ISR).
\end{abstract}

\footnotetext{
Corresponding author: Emmanouil S. Brilakis, MD, PhD, Dallas VA Medical Center (111A), 4500 South Lancaster Road, Dallas, TX 75216, Tel: (214) 857-1547, Fax: (214) 302-1341, esbrilakis@gmail.com.

Conflict of Interest:

Dr. Christopoulos: none

Dr. Karmpaliotis: speaker bureau, Abbott Vascular and Medtronic; consultant, Bridgepoint Medical.

Dr. Alaswad: consulting fees from Terumo and Boston Scientific; consultant, no financial, Abbott Laboratories.

Dr. Lombardi: equity with Bridgepoint Medical

Dr. Grantham: Speaking fees, consulting, and honoraria from Boston Scientific, Asahi Intecc. Research grants from Boston Scientific, Asahi Intecc, Abbott Vascular, Medtronic.

Dr. Rangan: none

Dr. Kotsia: none

Dr. Lembo: speaker bureau: Medtronic; advisory board Abbott Vascular and Medtronic.

Dr. Kandzari: research/grant support and consulting honoraria from Boston Scientific and Medtronic Cardiovascular, and research/ grant support from Abbott.

Dr. Lee: none.

Dr. Kalynych: none.

Dr. Carlson: none.

Dr. Garcia: consulting fees from Medtronic

Dr. Banerjee: research grants from Gilead and the Medicines Company; consultant/speaker honoraria from Covidien and Medtronic; ownership in MDCARE Global (spouse); intellectual property in HygeiaTel.

Dr. Thompson: consultant for Abbott Vascular, Bridgepoint, Terumo, Volcano; equity Bridgepoint Medical

Dr. Brilakis: consulting honoraria/speaker fees from Sanofi, Janssen, St Jude Medical, Terumo, Asahi, Abbott Vascular, and Boston Scientific; research grant from Guerbet; spouse is an employee of Medtronic.
} 
Background-PCI for in-stent total occlusive disease has traditionally been associated with low success rates. We sought to examine angiographic and procedural outcomes of patients who underwent CTO PCI due to ISR using the novel "hybrid" algorithm, and compare them with patients with de novo CTOs.

Methods-We examined 521 consecutive patients who underwent CTO PCI at 5 high volume PCI centers in the United States using the "hybrid" approach. Clinical, angiographic and procedural outcomes were compared between CTOs due to ISR and de novo CTOs.

Results-The target CTO was due to ISR in 57 of 521 patients (10.9\%). Compared to patients with de novo CTOs, those with CTO due to ISR had higher frequency of diabetes $(56.1 \%$ vs. $39.6 \%, \mathrm{p}=0.02)$ and less calcification (5.3\% vs. $16.2 \%, \mathrm{p}<0.001)$, but longer occlusion length [38 (29-55) vs. 30 (20-51), $\mathrm{p}=0.04$ ]. Technical success in the ISR and de novo group was $89.4 \%$ vs. 92.5\% ( $\mathrm{p}=0.43$ ), respectively; procedural success was $86.0 \%$ vs. $90.3 \%$ ( $\mathrm{p}=0.31$ ), respectively; and the incidence of major adverse cardiac events was $3.5 \%$ vs. $2.2 \%$ ( $\mathrm{p}=0.63)$, respectively.

Conclusions-Use of the "hybrid" approach to CTO PCI was associated with similarly high procedural success and similarly low major complication rates in patients with de novo and ISR CTOs.

\section{Keywords}

chronic total occlusion; in-stent restenosis; percutaneous coronary intervention

\section{Introduction}

Coronary chronic total occlusions (CTOs) due to in-stent restenosis (ISR) are common, representing $5 \%$ to $25 \%$ of all CTO percutaneous coronary interventions (PCI). (1-3).

However, PCI of CTOs due to ISR has been challenging, with low technical success rates (1,3-6) mainly due to difficulty with wire and balloon crossing (5). In addition, ISR CTO may require higher inflation pressures to overcome stent recoil generated from two stent layers (3). As a result, patients with ISR CTOs are often treated medically or referred for coronary artery bypass graft surgery. The recent development of the "hybrid approach" to CTO crossing has streamlined the crossing strategy selection and has increased the CTO PCI overall procedural success rates $(7,8)$, yet its impact on the percutaneous treatment of CTOs due to ISR has not yet been evaluated and formed the focus of the present study.

\section{Methods}

\section{“Hybrid” СTO patients}

We examined the clinical and angiographic records of consecutive patients who underwent CTO PCI between January 2012 and September 2013 by experienced high-volume operators at 5 CTO PCI centers in the United States: Appleton Cardiology, Appleton, Wisconsin; Piedmont Heart Institute, Atlanta, Georgia; St. Joseph Medical Center, Bellingham, Washington; St. Luke's Health System's Mid-America Heart Institute, Kansas City, Missouri; and VA North Texas Health Care System, Dallas, Texas. Data was collected both prospectively and retrospectively and recorded in a dedicated CTO registry (ClinicalTrials.gov Identifier: NCT02061436). CTO patients presented with stable angina, 
acute coronary syndrome or a positive stress test (Table I) and the decision to revascularize the CTO was made after discussion with the Heart Team. The study was approved by the Institutional Review Board of each participating center.

\section{Definitions}

Chronic total occlusions were defined as coronary obstructions with Thrombolysis in Myocardial Infarction (TIMI) flow grade 0 of at least 3 months duration. Estimation of the occlusion duration was based on first onset of anginal symptoms, prior history of myocardial infarction in the target vessel territory, or comparison with a prior angiogram. The CTO was considered to be due to ISR if the occlusion was located within a previously placed stent or within the $5 \mathrm{~mm}$ margins proximal and distal to the stent. The J-CTO score was calculated for each lesion based on occlusion length, stump morphology, presence of calcification, presence of tortuosity, and prior attempt to open the CTO.(9)

Technical success was defined as angiographic evidence of $<30 \%$ residual stenosis with restoration of TIMI 3 antegrade flow in the CTO target vessel. Procedural success was defined as technical success with no procedural major adverse cardiac effects, including death, Q-wave myocardial infarction (MI), recurrent cardiac symptoms requiring repeat target vessel PCI or coronary artery bypass graft surgery (CABG), cardiac tamponade requiring pericardiocentesis, and stroke.

\section{Statistical analysis}

Continuous data were reported as mean \pm standard deviation (normally distributed data) or median and interquartile range (non-normally distributed data) and compared using t-test or Wilcoxon rank-sum test, as appropriate. Categorical data were presented as frequencies or percentages and compared using chi square or Fisher's exact test, as appropriate. A twosided $\mathrm{p}$ value of $<0.05$ was considered statistically significant. All statistical analyses were performed using JMP version 11.0 (SAS Institute, Cary, North Carolina).

\section{Results}

\section{Clinical and angiographic characteristics}

From January 2012 to September 2013, 521 patients underwent CTO PCI at the study sites. Of those, 57 (10.9\%, 95\% confidence intervals $8.4 \%$ to $13.9 \%)$ had CTO due to ISR and 464 (89.1\%) had de novo CTOs. The presentation of the CTO patients is described in Table I. Mean age was $64.7 \pm 9.9$ years, $86.5 \%$ of the patients were men, $41.4 \%$ had diabetes mellitus, $38.4 \%$ had a history of prior MI, $62.6 \%$ had undergone prior PCI, and $36.2 \%$ had prior CABG. Of the $521 \mathrm{CTO}$ lesions, $15.0 \%$ had severe calcification and $6.5 \%$ had severe tortuosity. Median CTO occlusion length was 30 (20-53) $\mathrm{mm}$, and a prior unsuccessful CTO PCI attempt had been performed in $17.9 \%$ of patients. The mean J-CTO score was $2.7 \pm 1.2$. Compared to patients with de novo CTOs, patients with CTOs due to ISR had higher prevalence of diabetes $(56.1 \%$ vs. $39.6 \%, \mathrm{p}=0.02)$, and were less likely to have severe calcification (5.3\% vs. $16.2 \%, \mathrm{p}<0.001)$, but had longer occlusion length [38 (29-55) vs. 30 (20-51), $\mathrm{p}=0.04]$. 


\section{Procedural outcomes and complications}

Technical and procedural success was similar in patients with CTOs due to ISR and de novo CTOs, (technical success $89.4 \%$ vs. $92.5 \%$, $\mathrm{p}=0.43$; procedural success $86.0 \%$ vs. $90.3 \%$, $\mathrm{p}=0.31$ ). In successful cases, the most common crossing approach was antegrade wire escalation (41.1\%), followed by the retrograde approach (31.4\%), and antegrade resection and re-entry (27.4\%). The CrossBoss catheter was used in 29.8\% of cases. Stents were implanted in $97.7 \%$ of patients. Median fluoroscopy time and contrast volume were 41 (26-65) $\mathrm{min}$ and 260 (195-370) $\mathrm{mL}$, respectively; and median air kerma radiation dose was 3.79 (2.19-5.83) Gray.

Major adverse cardiac events were recorded in 12 of 521 (2.3\%) patients and occurred with similar frequency in both groups ( $3.5 \%$ vs. $2.2 \%$ for ISR and de novo CTO, respectively, $\mathrm{p}=0.63$ ). Two patients died, one of cardiac tamponade and unsuccessful pericardiocentesis, and one of vascular access complication that resulted in profound hemorrhage and hypovolemic shock. Acute MI was reported in 5 patients, one patient required emergency repeat PCI, 2 patients developed tamponade requiring pericardiocentesis, 2 patients developed severe bleeding resulting in hypotension, and one patient required cardiopulmonary resuscitation secondary to asystole (Table II).

\section{Discussion}

The main finding of this study is that use of the "hybrid" approach to CTO PCI resulted in equally high success and equally low complication rates in both ISR and de novo CTOs.

The prevalence of CTO due to ISR was $10.9 \%$ in our registry. In a study of 78 patients Abbas et al. reported a 25\% prevalence of CTOs due to ISR (1), whereas Wilson et al. reported a $14.9 \%$ prevalence of ISR in 349 CTO PCIs.(2) After review of the literature and personal databases, Werner et al. estimated that $5 \%$ to $10 \%$ of all CTOs were due to ISR (3). The exact rate of in-stent restenosis following PCI remains unknown to date. Shah et al. reported a $1.6 \%$ rate of bare metal stent total occlusion in 955 native coronary lesions at 6month angiographic follow-up (4). In the Stenting Of Saphenous vein grafts trial nearly 25\% of patients receiving bare metal stents developed occlusive restenosis (10).

There is limited published data on the success of ISR CTO PCI (Table III). Werner et al. showed a 70\% primary success in ISR CTOs compared to $85 \%$ in de novo lesions (3). Abbas et al. reported $63 \%$ procedural success in patients with CTOs due to ISR (1). Although success rates in patients with ISR CTO were similar to patients with de novo lesions ( $63 \%$ vs. $70 \%$ respectively, $\mathrm{p}=0.26$ ) inability to advance or fully dilate the balloon catheter was more common in the ISR group. Adbel-karim et al. reported a $71 \%$ procedural success rate in 21 patients undergoing PCI of CTOs due to ISR. In this study the antegrade approach was used in most patients, with only 2 of $21(9.5 \%)$ patients undergoing retrograde CTO PCI.

There are several potential explanations for the previously reported lower success rate for CTO PCI in ISR lesions compared to non-ISR lesions. First, as was also shown in our paper, CTOs due to ISR are longer. Second, they may be more calcified. Hakim et al. showed a 
$20 \%$ rate of neointimal calcification in 54 late drug-eluting stent restenotic lesions using serial gray scale intravascular ultrasound (11). Third, the presence of a prior stent could interfere with equipment advancement through the CTO. Restenting may be hindered by trapping of the new stent in the struts of the prior stent (12), or in cases of subintimal crossing of the CTO, true lumen re-entry may be hindered. In challenging cases, special maneuvers may be required involving either antegrade or retrograde penetration of the occluded stent and subsequent strut dilatation with "crushing" of the prior stents when new stents are deployed (13).

Our study demonstrates significantly higher success rates for ISR CTO PCI than previously published (89.4\% technical success, which was similar to the $92.5 \%$ technical success rate of non ISR CTOs). This in part reflects the expertise in CTO PCI of the participating centers and operators. It also highlights the positive impact of the "hybrid" algorithm, specifically the ability to promptly change the CTO crossing strategy if the initially selected strategy does not succeed within a reasonable period of time. Dissection/re-entry techniques were used in $30.6 \%$ and the retrograde approach in $30.6 \%$ of ISR CTO cases, suggesting that use of these novel strategies was critical to achieving high success rates. The CrossBoss catheter, used in $54.4 \%$ of ISR CTO cases and in $26.7 \%$ of de novo CTO cases in our registry, has been shown to be useful in PCI of ISR CTOs. Papayannis et al. reported successful crossing of CTOs due to ISR with the CrossBoss catheter in 5 of 6 attempted cases (14). Wilson et al. reported $87 \%$ technical success (27 of 31 CTOs) in CTOs due to ISR, with direct lumen-to-lumen crossing of the catheter in most cases (2). Importantly this high success rate was achieved with low fluoroscopy time (mean 29.6 \pm 15.1 minutes) and patient air kerma radiation exposure (3.32 Gray, interquartile range 1.92 to 5.77 .

Our study has limitations. It was observational, and only reported procedural outcomes without long-term follow-up. There was no clinical event adjudication by a clinical events committee. All procedures were performed in 5 high-volume PCI centers, highly skilled in all CTO PCI contemporary crossing technique and the "hybrid" algorithm. Therefore, the results of the current study may not be generalizable to PCI settings where experience with percutaneous treatment of CTO is more limited. Finally, the long-term outcomes of PCI CTO lesions due to ISR are unknown and it is possible that such lesions may have higher restenosis rates than de novo CTOs.

In conclusion, our study demonstrates that CTOs due to ISR can be effectively treated with the "hybrid" approach with similarly high procedural success and similarly low complication rates as de novo CTOs.

\section{Supplementary Material}

Refer to Web version on PubMed Central for supplementary material.

\section{Acknowledgments}

Data collection was performed using REDCap, which is supported by CTSA NIH Grant UL1-RR024982. 


\section{Abbreviation list}

$\begin{array}{ll}\text { CABG } & \text { Coronary Artery Bypass Grafting } \\ \text { CTO } & \text { Chronic Total Occlusion } \\ \text { ISR } & \text { In-stent Restenosis } \\ \text { MI } & \text { Myocardial Infarction } \\ \text { PCI } & \text { Percutaneous Coronary Intervention } \\ \text { TIMI } & \text { Thrombolysis in Myocardial Infarction }\end{array}$

\section{References}

1. Abbas AE, Brewington SD, Dixon SR, Boura J, Grines CL, O’Neill WW. Success, safety, and mechanisms of failure of percutaneous coronary intervention for occlusive non-drug-eluting in-stent restenosis versus native artery total occlusion. Am J Cardiol. 2005; 95(12):1462-6. [PubMed: 15950572]

2. Wilson W, Walsh S, Hanratty C, Strange J, Hill J, Sapontis J, Spratt J. A novel approach to the management of occlusive in-stent restenosis (ISR). Eurointervention. 2013 In press.

3. Werner GS, Moehlis H, Tischer K. Management of total restenotic occlusions. EuroIntervention. 2009; 5(Suppl D):D79-83. [PubMed: 19736077]

4. Shah PB, Cutlip DE, Popma JJ, Kuntz RE, Ho KKL. Incidence and predictors of late total occlusion following coronary stenting. Catheterization and Cardiovascular Interventions. 2003; 60(3):344351. [PubMed: 14571485]

5. Dangas GD, Claessen BE, Caixeta A, Sanidas EA, Mintz GS, Mehran R. In-stent restenosis in the drug-eluting stent era. J Am Coll Cardiol. 2010; 56(23):1897-907. [PubMed: 21109112]

6. Abdel-karim AR, Lombardi WB, Banerjee S, Brilakis ES. Contemporary outcomes of percutaneous intervention in chronic total coronary occlusions due to in-stent restenosis. Cardiovasc Revasc Med. 2011; 12(3):170-6. [PubMed: 21640935]

7. Brilakis ES, Grantham JA, Rinfret S, Wyman RM, Burke MN, Karmpaliotis D, Lembo N, Pershad A, Kandzari DE, Buller CE. A percutaneous treatment algorithm for crossing coronary chronic total occlusions. JACC Cardiovasc Interv. 2012; 5(4):367-79. and others. [PubMed: 22516392]

8. Menon RV, Alaswad K, Lombardi W, Mishoe KL, Grantham JA, Marso SP, Rutherford B, Patel SM, Pokala NR, Rangan B. The Safety And Efficacy Of The "Hybrid Approach" To Chronic Total Occlusions: Insights From A Contemporary Multicenter US Registry. Journal of the American College of Cardiology. 2013; 62(18_S1):B119-B119. others.

9. Morino Y, Kimura T, Hayashi Y, Muramatsu T, Ochiai M, Noguchi Y, Kato K, Shibata Y, Hiasa Y, Doi O. In-hospital outcomes of contemporary percutaneous coronary intervention in patients with chronic total occlusion insights from the J-CTO Registry (Multicenter CTO Registry in Japan). JACC Cardiovasc Interv. 2010; 3(2):143-51. others. [PubMed: 20170870]

10. Brilakis ES, Lichtenwalter C, de Lemos JA, Roesle M, Obel O, Haagen D, Saeed B, Gadiparthi C, Bissett JK, Sachdeva R. A randomized controlled trial of a paclitaxel-eluting stent versus a similar bare-metal stent in saphenous vein graft lesions the SOS (Stenting of Saphenous Vein Grafts) trial. J Am Coll Cardiol. 2009; 53(11):919-28. others. [PubMed: 19281920]

11. Hakim DA, Mintz GS, Sanidas E, Rusinova R, Weisz G, Leon MB, Moses JW, Stone GW, Maehara A. Serial gray scale intravascular ultrasound findings in late drug-eluting stent restenosis. Am J Cardiol. 2013; 111(5):695-9. [PubMed: 23273714]

12. Watabe H, Sato A, Hoshi T, Obara K, Kawamura R, Aonuma K. Dislodged and mechanically distorted stent stuck within a previously implanted drug-eluting stent. Heart and Vessels. 2013; 28(4):541-545. [PubMed: 22993105] 
13. Ohya H, Kyo E, Katoh O. Successful bypass restenting across the struts of an occluded subintimal stent in chronic total occlusion using a retrograde approach. Catheter Cardiovasc Interv. 2013; 82(5):E678-E683. [PubMed: 23704039]

14. Papayannis A, Banerjee S, Brilakis ES. Use of the crossboss catheter in coronary chronic total occlusion due to in-stent restenosis. Catheterization and Cardiovascular Interventions. 2012; 80(2):E30-E36. [PubMed: 22162302] 
Table I

Baseline clinical and angiographic characteristics

\begin{tabular}{|c|c|c|c|c|}
\hline Variable & $\begin{array}{l}\text { Overall } \\
(n=521)\end{array}$ & $\begin{array}{c}\text { In-stent } \\
\text { restenosis } \\
\text { CTOs }(\mathbf{n}=57)\end{array}$ & $\begin{array}{c}\text { De novo } \\
\text { CTOs }(n=464)\end{array}$ & $P$ \\
\hline Age (years) & $64.7 \pm 9.9$ & $64.4 \pm 9.7$ & $64.8 \pm 9.9$ & 0.75 \\
\hline Male $(\%)$ & 86.5 & 84.2 & 86.8 & 0.59 \\
\hline Diabetes (\%) & 41.4 & 56.1 & 39.6 & 0.02 \\
\hline Dyslipidemia (\%) & 95.0 & 100.0 & 94.4 & 0.10 \\
\hline Hypertension (\%) & 90.5 & 93.0 & 90.2 & 0.64 \\
\hline Prior MI (\%) & 38.4 & 45.6 & 37.5 & 0.24 \\
\hline Prior PCI (\%) & 62.6 & 100.0 & 58.0 & $<0.001$ \\
\hline Prior CABG (\%) & 36.2 & 29.8 & 36.9 & 0.29 \\
\hline Prior valve surgery $(\%)$ & 2.9 & 5.3 & 2.6 & 0.22 \\
\hline $\operatorname{LVEF}(\%)$ & $51 \pm 13$ & $55 \pm 12$ & $50 \pm 13$ & 0.01 \\
\hline Prior Stroke (\%) & 10.4 & 7.0 & 10.9 & 0.49 \\
\hline $\operatorname{PAD}(\%)$ & 17.8 & 12.5 & 18.5 & 0.36 \\
\hline Current Smoking (\%) & 39.0 & 29.8 & 40.1 & 0.16 \\
\hline $\begin{array}{l}\text { Baseline creatinine } \\
(\mathrm{mg} / \mathrm{dL})\end{array}$ & $1.14 \pm 0.66$ & $1.08 \pm 0.25$ & $1.14 \pm 0.70$ & 0.31 \\
\hline \multicolumn{5}{|l|}{ CTO vessel } \\
\hline LAD $(\%)$ & 19.8 & 19.3 & 19.8 & \multirow[t]{4}{*}{0.02} \\
\hline $\operatorname{LCX}(\%)$ & 13.4 & 17.5 & 12.9 & \\
\hline $\mathrm{RCA}(\%)$ & 60.1 & 56.1 & 60.6 & \\
\hline Other $(\%)$ & 6.7 & 7.1 & 6.7 & \\
\hline $\begin{array}{l}\text { Severe calcification } \\
\text { ( } \geq 50 \% \text { reference lesion } \\
\text { diameter) }(\%)\end{array}$ & 15.0 & 5.3 & 16.2 & $<0.001$ \\
\hline $\begin{array}{l}\text { Severe proximal } \\
\text { tortuosity }(2 \text { bends }>90 \\
\text { deg or } 1 \text { bend }>120 \text { deg }) \\
(\%)\end{array}$ & 6.5 & 5.4 & 6.6 & 0.63 \\
\hline $\begin{array}{l}\text { CTO occlusion length } \\
(\mathrm{mm})\end{array}$ & $30(20-53)$ & $38(29-55)$ & $30(20-51)$ & 0.04 \\
\hline $\begin{array}{l}\text { CTO lesion age based } \\
\text { on angiography } \\
\text { (months) }\end{array}$ & $20.5(3.0-73.0)$ & $32(2.5-76.3)$ & $\begin{array}{c}18.5(3.0 \\
70.8)\end{array}$ & 0.82 \\
\hline $\begin{array}{l}\text { Prior attempt to open } \\
\text { CTO }(\%)\end{array}$ & 17.9 & 24.6 & 15.8 & 0.09 \\
\hline CAD presentation & & & & \multirow{6}{*}{0.99} \\
\hline Acute coronary & & & & \\
\hline syndrome $(\%)$ & 15 & 14 & 15 & \\
\hline Stable angina $(\%)$ & 69 & 70 & 69 & \\
\hline $\begin{array}{l}\text { Symptoms unlikely to be } \\
\text { ischemic (\%) }\end{array}$ & 7 & 7 & 7 & \\
\hline Asymptomatic (\%) & 9 & 9 & 9 & \\
\hline
\end{tabular}




\begin{tabular}{|lcccc|}
\hline Variable & $\begin{array}{c}\text { Overall } \\
(\mathbf{n = 5 2 1})\end{array}$ & $\begin{array}{c}\text { In-stent } \\
\text { restenosis } \\
\text { CTOs (n=57) }\end{array}$ & $\begin{array}{c}\text { De novo } \\
\text { CTOs (n=464) }\end{array}$ & $\boldsymbol{P}$ \\
\hline Positive (\%) & 95 & 87 & 96 & \\
Negative (\%) & 3 & 8 & 2 & 0.16 \\
Indeterminate & 2 & 4 & 2 & \\
J-CTO score & $2.7 \pm 1.2$ & $2.8 \pm 1.3$ & $2.6 \pm 1.2$ & 0.50 \\
\hline
\end{tabular}

Values are mean \pm standard deviation or median (interquartile range)

MI: myocardial infarction; PCI: percutaneous coronary intervention, CABG: coronary artery bypass grafting; LVEF; left ventricular ejection fraction; PAD: peripheral arterial disease; CTO: chronic total occlusion; LAD: left anterior descending artery; LCX: left circumflex artery; RCA: right coronary artery; CAD: coronary artery disease

*

stress test results were available for 444 patients 
Table II

Procedural outcomes

\begin{tabular}{|lcccc|}
\hline \multicolumn{1}{|c}{ Variable } & $\begin{array}{c}\text { Overall } \\
(\mathbf{n = 5 2 1})\end{array}$ & $\begin{array}{c}\text { In-stent } \\
\text { restenosis } \\
(\mathbf{n = 5 7})\end{array}$ & $\begin{array}{c}\text { Primary } \\
\text { lesions } \\
(\mathbf{n = 4 6 4})\end{array}$ & P \\
\hline Successful approach & & & & \\
Antegrade wiring (\%) & 41.1 & 35.3 & 41.8 & \\
$\begin{array}{l}\text { Antegrade dissection } \\
\text { and re-entry (\%) }\end{array}$ & 27.4 & 33.3 & 26.7 & 0.93 \\
Retrograde (\%) & 31.4 & 31.4 & 31.4 & \\
Stenting in successful & & & & \\
cases (\%) & 97.7 & 96.1 & 97.9 & 0.55 \\
Total stents implanted (N) & 1,181 & 111 & 1,070 & N/A \\
DES (\%) & 99.8 & 100.0 & 99.7 & N/A \\
BMS (\%) & 0.2 & 0.0 & 0.2 & N/A \\
Stents per patient (N) & $2.6 \pm 1.1$ & $2.4 \pm 1.0$ & $2.6 \pm 1.1$ & 0.08 \\
Fluoroscopy time (min) & $41(26-65)$ & $34(21-70)$ & $41(27-65)$ & 0.47 \\
Contrast volume (mL) & $260(195-370)$ & $230(175-344)$ & $265(200-375)$ & 0.09 \\
$\begin{array}{l}\text { Air Kerma Radiation dose } \\
\text { (Gray) }\end{array}$ & $3.79(2.19-$ & $3.32(1.92-$ & $3.87(2.20-$ & 0.34 \\
$\begin{array}{l}\text { Dose Area Product } \\
\text { Fluoroscopy dose (Gray- } \\
\left.\text { cm }{ }^{2}\right)\end{array}$ & $5.83)$ & $5.77)$ & $5.87)$ & \\
Technical Success (\%) & $270(158-413)$ & $240(138-369)$ & $285(161-427)$ & 0.26 \\
Procedural Success (\%) & 92.1 & 89.4 & 92.5 & 0.43 \\
MACE(\%) & 89.8 & 86.0 & 90.3 & 0.31 \\
\hline & 2.3 & 3.5 & 2.2 & 0.63 \\
\hline
\end{tabular}

Values are mean \pm standard deviation or median (interquartile range).

BMS: bare metal stents; DES: drug-eluting stents; MACE: major adverse cardiac effects 
Table III

Comparison of success rates of chronic occlusive in-stent restenosis in previous studies.

\begin{tabular}{|l|c|c|c|l|}
\hline \multicolumn{1}{|c|}{ Author } & Year & $\begin{array}{c}\text { Prevalence of } \\
\text { ISR CTO }\end{array}$ & Success rate & Wire/Catheter Technique \\
\hline Yang et al.(15) & 2004 & Not reported & $5 / 5(100 \%)$ & Front runner catheter \\
\hline Abbas et al.(3) & 2005 & $25 \%$ & $49 / 78(63 \%)$ & Not described \\
\hline Werner et al.(4) & 2009 & $5-10 \%$ & $70 \%$ & Not described \\
\hline $\begin{array}{l}\text { Adbel-karim et } \\
\text { al(5) }\end{array}$ & 2010 & Not reported & $15 / 21(71 \%)$ & $\begin{array}{l}\text { Whisper, Confianza Pro 12, } \\
\text { Cross it 100, Pilot 200, } \\
\text { guidewrough, Stingray }\end{array}$ \\
\hline Brilakis et al.(16) & 2010 & Not reported & $2 / 2(100 \%)$ & $\begin{array}{l}\text { Venture catheter / Stingray } \\
\text { guidewire }\end{array}$ \\
\hline $\begin{array}{l}\text { Papayannis et } \\
\text { al.(14) }\end{array}$ & 2011 & Not reported & $6 / 6(100 \%)$ & CrossBoss catheter \\
\hline Subinas et al.(17) & 2013 & Not reported & $\begin{array}{l}133 / 156 \\
(85.2 \%)\end{array}$ & Not described \\
\hline Wilson et al.(9) & 2013 & $14.9 \%$ & $27 / 31(87 \%)$ & CrossBoss catheter \\
\hline
\end{tabular}

